\title{
Isolation and characterization of the perforatorium of rat spermatozoa
}

\author{
G. E. Olson, D. W. Hamilton and D. W. Fawcett \\ Department of Anatomy and Laboratory of Human Reproduction and Reproductive Biology, \\ Harvard Medical School, Boston, Massachusetts 02115, U.S.A.
}

\begin{abstract}
Summary. The perforatorium of rat spermatozoa was isolated and its protein composition determined. SDS-polyacrylamide gel electrophoresis showed that the organelle is composed of a single polypeptide component with a molecular weight of 13,000 . The perforatorium becomes more resistant to solubilization during epididymal transit due to an apparent increase in disulphide bond content. Amino acid analysis of the perforatorium polypeptide revealed a content of $6.5 \%$ cysteine.
\end{abstract}

\section{Introduction}

The head of the mammalian spermatozoon is a remarkably compact structure and in most species it is composed predominantly of two organelles, the acrosome and nucleus. In some rodents, however, such as the rat, mouse and hamster, which possess falciform sperm heads, the subacrosomal space at the anterior end of the nucleus and along the lateral margins of the nucleus contains a substantial amount of homogeneous electron-dense material (Fawcett, 1970). This material has been referred to as the perforatorium because it corresponds in location to the well defined structure found in the subacrosomal space of the spermatozoa of some non-mammalian vertebrates. This perinuclear material appears to be present in sperm heads of other mammalian species but is not as extensive as in rodent spermatozoa (Calvin \& Bedford, 1971).

Although a considerable amount of work has focused on the biochemical characterization of sperm nuclear proteins (Coelingh et al., 1969, 1972; Kistler, Geroch \& Williams-Ashman, 1973), little is known of the composition of the perforatorium. Early biochemical and cytochemical studies demonstrated that the mammalian sperm head is resistant to solubilization by various agents, possibly because of the keratin-like nature of the cysteine-rich component proteins (see Mann, 1964, for review). These early studies suggested that membranes were the resistant component of the sperm head (Green, 1940), a belief which accords with the subsequent description of the perforatorium as an extension of the nuclear membrane (Clermont, Einberg, Leblond \& Wagner, 1955). Careful observation with the light microscope established that the perforatorium of the rat spermatozoon is an extraordinarily resistant structure and is not solubilized even by extraction with strong alkali (Austin \& Bishop, 1958). However, subsequent ultrastructural studies have shown that the perforatorium is not a membrane, but is a homogeneous, finely granular component overlying the anterior portion of the nucleus (Fawcett, 1970) and has to be treated with a disulphide-reducing agent before it can be solubilized or dispersed (Calvin \& Bedford, 1971; Bedford \& Calvin, 1974).

In the present study we have isolated and analysed perforatorium material from rat spermatozoa, and demonstrated changes in its properties as the spermatozoa pass through the epididymis.

\section{Materials and Methods}

Spermatozoa were obtained from the caput or cauda epididymidis of freshly killed rats (Charles River, Wilmington, Massachusetts, U.S.A.). The spermatozoa were washed by gentle centrifugation at $500 \mathrm{~g}$ for $10 \mathrm{~min}$ in phosphate-buffered saline (PBS: $0.145 \mathrm{M}-\mathrm{NaCl}$ and $0.01 \mathrm{M}-\mathrm{Na}_{2} \mathrm{HPO}_{4}, \mathrm{pH} 7 \cdot 2$ ). 
The heads of spermatozoa were isolated by the following procedure. Whole spermatozoa in PBS were sonicated for 15 -sec bursts $\left(100 \mathrm{~W}\right.$ at $4^{\circ} \mathrm{C}$ ) in a Braun sonicator; samples were viewed by phasecontrast microscopy to determine the percentage of detached heads. When nearly all the heads were detached the sample was mixed with 3 volumes of a solution of $65 \%(\mathrm{w} / \mathrm{v})$ sucrose, $1 \mathrm{~mm}$-EDTA, $50 \mathrm{~mm}$-sodium acetate, $\mathrm{pH} 6.5$. Aliquots $(3 \mathrm{ml})$ of this suspension were layered over sucrose step gradients composed of $3 \mathrm{ml}$ aliquots of $65 \%, 70 \%$, and $75 \%$ sucrose in $1 \mathrm{~mm}$-EDTA, $50 \mathrm{~mm}$-sodium acetate, $\mathrm{pH} 6.5$. The gradients were then centrifuged in a swinging bucket rotor at $130,000 \mathrm{~g}$ for $60 \mathrm{~min}$. The sperm heads formed an annular pellet while the flagellar components remained at the step interfaces. The isolated sperm heads or whole spermatozoa were then extracted by one of the various protocols listed below.

(1) Sarkosyl extraction. Intact spermatozoa or isolated sperm heads were suspended in a solution of $1 \%$ sodium lauryl sarcosine (sarkosyl) (Sigma, St Louis, Missouri, U.S.A.), 2 mm-dithiothreitol (DTT) (Sigma), and $50 \mathrm{~mm}$-sodium borate, pH 9.0, at $4^{\circ} \mathrm{C}$. At intervals up to $2 \mathrm{hr}$ aliquots of the sperm suspension were removed, centrifuged at $50,000 \mathrm{~g}$ for $10 \mathrm{~min}$ and the pellets used for sodium dodecyl sulphate (SDS)-gel electrophoresis and electron or light microscopy.

(2) Triton $X-100$ extraction. Spermatozoa were suspended in a solution of $1 \%$ Triton X-100 (Sigma), $100 \mathrm{~mm}-\mathrm{NaCl}, 30 \mathrm{~mm}$-tris- $\mathrm{HCl}, \mathrm{pH} 9 \cdot 0$, and $2.0 \mathrm{~mm}-\mathrm{DT} T$ for $30 \mathrm{~min}$ at $4^{\circ} \mathrm{C}$. The spermatozoa were pelleted at $1000 \mathrm{~g}$ for $15 \mathrm{~min}$ and the pellet resuspended in $100 \mathrm{~mm}-\mathrm{NaCl}, 30 \mathrm{~mm}$-tris- $\mathrm{HCl}$, pH 9.0, and then pelleted again. The pellets were then used in the next extraction step, prepared for SDS-polyacrylamide gel electrophoresis, or used for light or electron microscopy.

(3) Guanidine- $\mathrm{HCl}$ extraction. Triton-extracted spermatozoa were suspended in a solution of 1 or $2 \mathrm{M}$-guanidine-HCl (Sigma) containing $10 \mathrm{~mm}-\mathrm{DTT}$ and $50 \mathrm{~mm}$-tris-HCl, $\mathrm{pH} \mathrm{9 \cdot 0.} \mathrm{After} 1 \mathrm{hr}$ at $4^{\circ} \mathrm{C}$ the nonsolubilized sperm components were pelleted at $50,000 \mathrm{~g}$ for $20 \mathrm{~min}$ and the pellets used for SDS-polyacrylamide gel electrophoresis.

(4) Urea extraction. Triton-treated spermatozoa were extracted for $1 \mathrm{hr}$ at $4^{\circ} \mathrm{C}$ with 4 or $6 \mathrm{M}$-urea (Schwarz-Mann, Orangeburg, New York, U.S.A.) containing 10 mM-DTT, 50 mm-tris-HCl, pH 9.0. The mixture was then centrifuged at $50,000 \mathrm{~g}$ for $20 \mathrm{~min}$ and the pellet used for SDS-polyacrylamide gel electrophoresis.

(5) SDS extraction. Spermatozoa from the caput or cauda epididymidis were extracted for $30 \mathrm{~min}$ in a solution of $1 \% \mathrm{SDS}, 20 \mathrm{mM}$-tris- $\mathrm{HCl}, \mathrm{pH} 9 \cdot 0$. The resistant sperm components were pelleted at $20,000 \mathrm{~g}$ for $20 \mathrm{~min}$ and the pellets used for SDS-polyacrylamide gel electrophoresis.

(6) Enzyme digestion. All enzyme digestions were performed on Triton X-100-extracted spermatozoa. Trypsin, chymotrypsin, papain and pepsin (Sigma) were used at a concentration of $1 \mathrm{mg} / \mathrm{ml}$ at room temperature.

\section{Light and electron microscopy}

Whole spermatozoa or sperm fractions were fixed with $5 \%$ glutaraldehyde buffered with collidine, postfixed with $1 \% \mathrm{OsO}_{4}$, dehydrated through ethanol and propylene oxide, and embedded in Epon 812. Thin sections were cut on an LKB-Huxley ultramicrotome, stained with uranyl acetate and lead citrate, and examined in a Siemens Elmskop 1A. Whole mount preparations of extracted spermatozoa were prepared by touching a drop of the suspension to a carbon-coated grid. The material adhering to the grid was fixed with $5 \%$ glutaraldehyde, stained with $3 \%$ uranyl acetate, dehydrated, and either air dried or critical-point dried from liquid $\mathrm{CO}_{2}$. Photomicrographs were taken on a Zeiss Universal phase-contrast microscope.

\section{Electrophoresis}

SDS-polyacrylamide electrophoresis was performed according to the procedure of Fairbanks, Steck \& Wallach (1971). Protein samples were heated to $100^{\circ} \mathrm{C}$ for $5 \mathrm{~min}$ in a solution of $1 \% \mathrm{SDS}$, 10 mm-tris-HCl, pH 8.0, 1 mM-EDTA and 40 mM-DTT. Samples were layered on $5.6 \%$ acrylamide gels $(5 \mathrm{~mm}$ i.d. $\times 12 \mathrm{~cm})$ and electrophoresed with a current of $6 \mathrm{~mA} / \mathrm{gel}$. Gels were fixed according to the method of Fairbanks et al. (1971) and stained with Coomassie Brilliant Blue. 


\section{Amino acid analysis}

Aliquots $(1 \mathrm{ml})$ of protein samples in $1 \%$ SDS, 1 mM-EDTA, $10 \mathrm{~mm}$-tris $-\mathrm{HCl}, \mathrm{pH} 8.0$, were adjusted to $5 \mathrm{~mm}$ in DTT and incubated at $50^{\circ} \mathrm{C}$ for $10 \mathrm{~min}$ before addition of $175 \mu \mathrm{l} 0 \cdot 1 \mathrm{M}$-iodoacetic acid in $1 \mathrm{~N}-\mathrm{NaOH}$ for reaction for $1 \mathrm{hr}$ at room temperature. The reaction was terminated by addition of excess mercaptoethanol. The protein sample was dialysed against double-distilled water, freeze dried, and then hydrolysed with $6.7 \mathrm{~N}-\mathrm{HCl}$ at $105^{\circ} \mathrm{C}$ for $18 \mathrm{hr}$. The hydrolysate was analysed for its amino acid composition in a Beckman amino acid analyser.

\section{Results and Discussion}

\section{Morphological observations}

The acrosome of the intact rat spermatozoon shows regions of varied electron density. Most of the acrosome has an amorphous substructure but along the convex margin of the nucleus some acrosomal material is arranged into a prominent crystalline structure (Pl. 1, Figs 1 and 2). The perforatorium, at the apical end of the nucleus, is generally homogeneous and amorphous, electrondense material (Pl. 1, Figs 1 and 2).

Treatment of intact rat spermatozoa with a solution containing the detergent sarkosyl and DTT results in the sequential solubilization of several sperm structures. First, the heads and tails become detached (Pl. 3, Fig. 5). In the flagellar region the sperm plasma membrane, the mitochondrial sheath, the central pair of microtubules of the axoneme, and the fibrous sheath are the most rapidly solubilized organelles, whilst the most resistant structures are the outer dense fibres, connecting piece, and some axoneme doublet microtubules (Pl. 2, Fig. 3). Sarkosyl-DTT extraction for 2 hr results in the solubilization of the remaining flagellar structures.

The sperm heads show characteristic morphological changes when treated with sarkosyl-DTT. Within $5 \mathrm{~min}$ the sperm heads begin to swell; the swelling begins at the posterior margin of the nucleus and proceeds anteriorly (Pl. 3, Figs 6 and 7). During the early stages of nuclear swelling the chromatin appears generally diffuse but contains some dark spots; these are formed by aggregations of very fine chromatin filaments (PI. 2, Fig. 3). Even after swelling to several times its original size, the nucleus maintains a shape reminiscent of the intact, condensed sperm head (Pl. 3, Figs 5 and 7). Within 30 min of treatment with sarkosyl, the granularity of the nucleus disappears and the chromatin becomes dispersed and difficult to see at the light microscope level; ultrastructurally it appears as a homogeneous network of fine filaments.

As the nucleus swells during treatment with sarkosyl-DTT, a rigid structure of regular shape becomes detached from the anterior part of the sperm head and remains intact in the detergent solution (PI. 3, Figs 5 and 7). The structure retains the curvature of the intact sperm head and appears to have three separate prongs joined together at the anterior tip of the structure (Pl. 3, Figs 5 and 7 ). Electron micrographs of thin sections and whole mount preparations of sarkosyl-treated spermatozoa show that this detached head structure is the perforatorium (P1. 2, Figs 3 and 4). In cross-section the anterior end of the perforatorium shows a characteristic triangular shape (Pl. 2, Fig. 3, insert). The matrix is generally amorphous but relatively homogeneous in appearance (PI. 2, Figs 3 and 4); small areas may appear devoid of matrix material (Pl. 2, Fig. 3, insert).

The effects of the anionic detergent, SDS, on sperm morphology have previously been noted (Calvin \& Bedford, 1971), and the present effects with sarkosyl are very similar. However, sarkosylDTT, unlike SDS-DTT, does not cause the rapid dissolution of the perforatorium but rather leaves it intact and accessible for chemical analysis.

\section{SDS-polyacrylamide gel electrophoresis}

Concomitant with the morphological observations, SDS-polyacrylamide gel electrophoresis also shows that specific sperm proteins are sequentially solubilized during sarkosyl-DTT extraction. After $30 \mathrm{~min}$, several minor sperm proteins have been solubilized but the major bands persist (Pl. 4, 
Fig. 8B). After extraction for $60 \mathrm{~min}$, when the outer dense fibres are the only major morphologically identifiable sperm component, only four major polypeptide bands which range in molecular weight from 87,000 to 11,000 remain (Pl. 4, Fig. $8 \mathrm{C}$ ).

Analysis of isolated sperm heads after a 30-min sarkosyl-DTT extraction, when the perforatorium is still visible by light microscopy and the nuclei fully decondensed, shows a single major band of a polypeptide of molecular weight 13,000 (Pl. 4, Fig. 8D). This corresponds to band $\mathbf{P}$ on Pl. 4, Figs $8 \mathrm{~A}$ and $8 \mathrm{~B}$. Overloaded gels reveal only trace amounts of 2 or 3 high molecular weight polypeptides. The perforatorium therefore appears to be composed of a single polypeptide component. As determined by electron microscopy, the polypeptide of molecular weight 13,000 was only found in SDS gels of sperm fractions which contained an intact perforatorium as one of the fraction components.

The resistance of the perforatorium protein to solubilization by several different agents as well as its susceptibility to proteolytic digestion was assessed by electron microscopy and SDS-polyacrylamide gel electrophoresis, and the results are presented in Table 1. Typically, a disulphide bondreducing reagent in addition to the solubilizing agents tested is required to solubilize the perforatorium.

Table 1. Solubility properties of the perforatorium of rat spermatozoa

\begin{tabular}{|c|c|c|}
\hline Agent & $\begin{array}{l}\text { Length of extraction } \\
\text { or digestion }\end{array}$ & $\begin{array}{l}\text { Protein solubilized } \\
\text { or hydrolysed }\end{array}$ \\
\hline $1 \%$ Triton X-100 +2 mm-DTT & $1 \mathrm{hr}$ & No \\
\hline $1 \%$ SDS & $1 \mathrm{hr}$ & No \\
\hline $1 \%$ SDS + 2 mM-DTT & $15 \mathrm{~min}$ & Yes \\
\hline 4 м-urea + 10 mм-DTT* & $1 \mathrm{hr}$ & No \\
\hline $6 \mathrm{~m}$-urea $+10 \mathrm{~mm}$-DTT* & $1 \mathrm{hr}$ & Yes \\
\hline 1 M-guanidine- $\mathrm{HCl}+10 \mathrm{~mm}$-DTT* & $1 \mathrm{hr}$ & No \\
\hline $2 \mathrm{M}$-guanidine- $\mathrm{HCl}+10 \mathrm{~mm}-\mathrm{DTT} *$ & $1 \mathrm{hr}$ & Yes \\
\hline Trypsin & $30 \mathrm{~min}$ & Yes \\
\hline Chymotrypsin & $30 \mathrm{~min}$ & Yes \\
\hline Papain & $30 \mathrm{~min}$ & Yes \\
\hline Pepsin & $30 \mathrm{~min}$ & Yes \\
\hline
\end{tabular}

* Sperm first extracted for $1 \mathrm{hr}$ with $1 \%$ Triton X-100 and 2 mM-DTT.

Changes during passage through the epididymis

Spermatozoa from the caput or cauda epididymidis were extracted in equivalent solutions containing $1 \%$ SDS but no DTT, and after extraction for $30 \mathrm{~min}$ the nonsolubilized sperm proteins were pelleted and analysed by SDS-polyacrylamide gel electrophoresis. A typical result is shown in P1. 4, Figs $8 E$ and $8 F$; the gels show that SDS without DTT solubilizes the 13,000 molecular weight protein of caput spermatozoa but not that of cauda spermatozoa.

Table 2. Amino acid composition of perforatorium of rat spermatozoa

\begin{tabular}{lc|lc}
\hline Amino acid & \% of total & Amino acid & \% of total \\
\hline Lysine & $3 \cdot 8$ & Alanine & $5 \cdot 4$ \\
Arginine & $3 \cdot 8$ & Valine & $7 \cdot 3$ \\
Cysteine & $6 \cdot 5$ & Isoleucine & $5 \cdot 7$ \\
Aspartic acid & $9 \cdot 0$ & Leucine & 6.9 \\
Threonine & $7 \cdot 3$ & Phenylalanine & $3 \cdot 1$ \\
Serine & $7 \cdot 9$ & Proline & $8 \cdot 2$ \\
Glutamic acid & $14 \cdot 0$ & Methionine & $1 \cdot 8$ \\
Glycine & $7 \cdot 9$ & Tyrosine & $1 \cdot 7$ \\
\hline
\end{tabular}




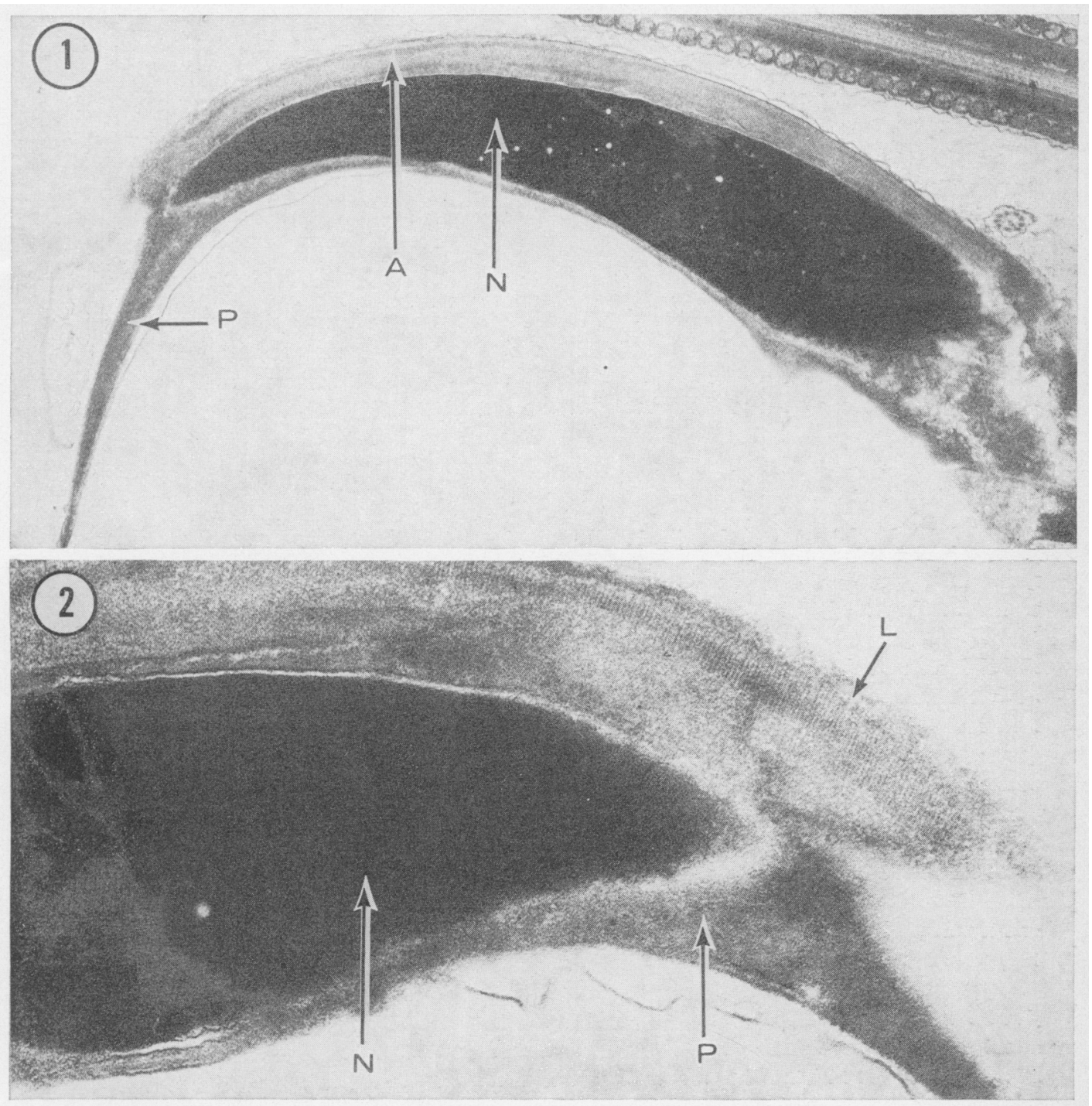

Fig. 1. Electron micrograph of intact rat sperm head showing highly condensed nucleus (N), acrosome (A), and perforatorium $(\mathrm{P})$.

Fig. 2. View of anterior end of rat sperm head showing the abundant amorphous material of the perforatorium $(P)$ which overlies the nucleus $(N)$. Note also the acrosome which contains a prominent crystalline lamina (L) as well as a homogeneous electron-dense matrix. 
PLATE 2

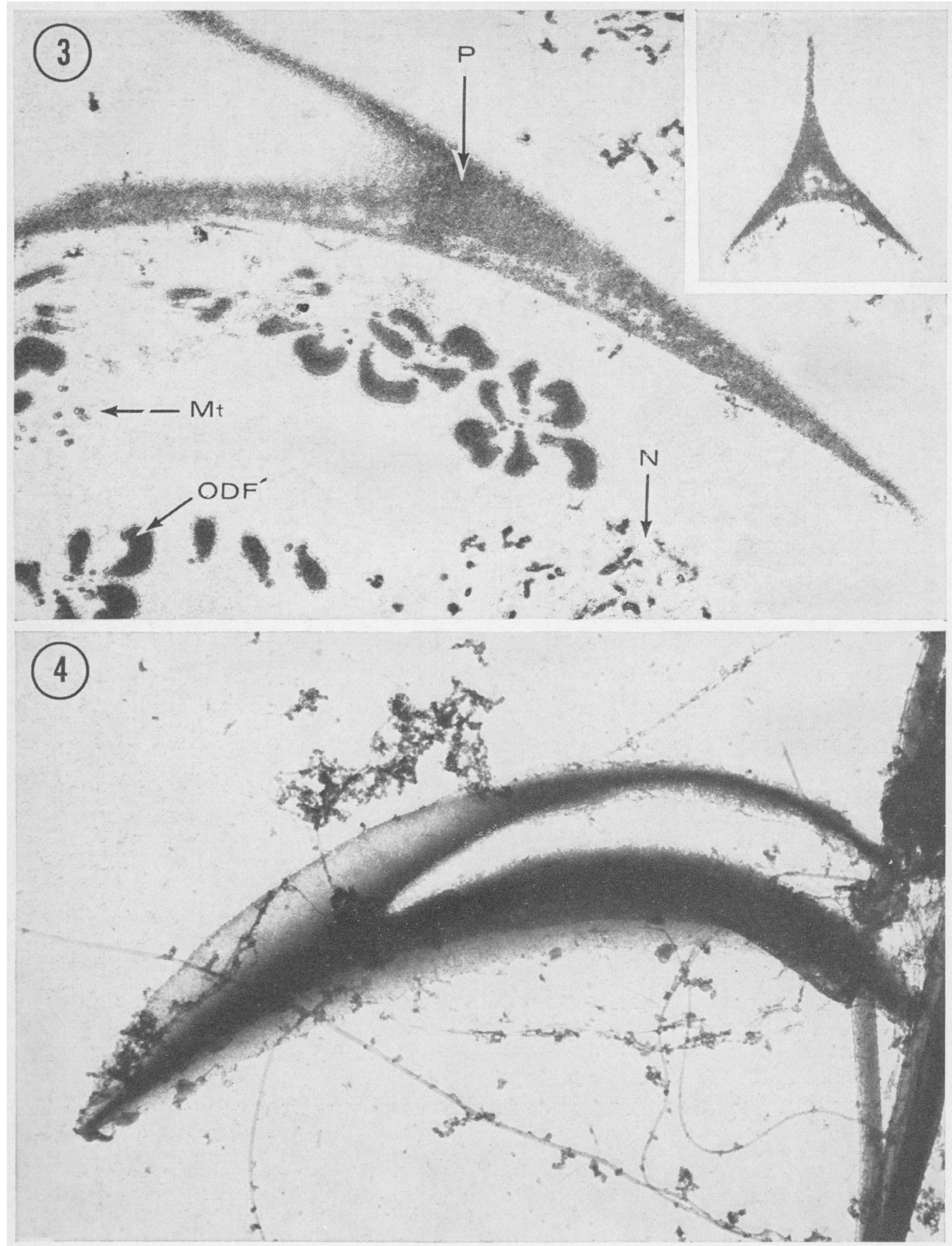

Fig. 3. Thin section of rat sperm organelles not solubilized by 15 min extraction in $1 \%$ sarkosyl, 2 mmDTT, $20 \mathrm{~mm}$-tris- $\mathrm{HCl}, \mathrm{pH} 9 \cdot 0$. Intact organelles are the outer dense fibres (ODF), axoneme doublet microtubules $(\mathrm{Mt})$, decondensed nucleus displaying some granularity $(\mathrm{N})$, and the perforatorium (P). Inset: cross-section of perforatorium showing its triangular outline.

Fig. 4. Whole-mount electron micrograph of perforatorium from rat spermatozoon treated with $1 \%$ sarkosyl +2 mm-DTT. Note that the structure appears rigid and has retained the curvature of the intact sperm head. 
PLATE 3

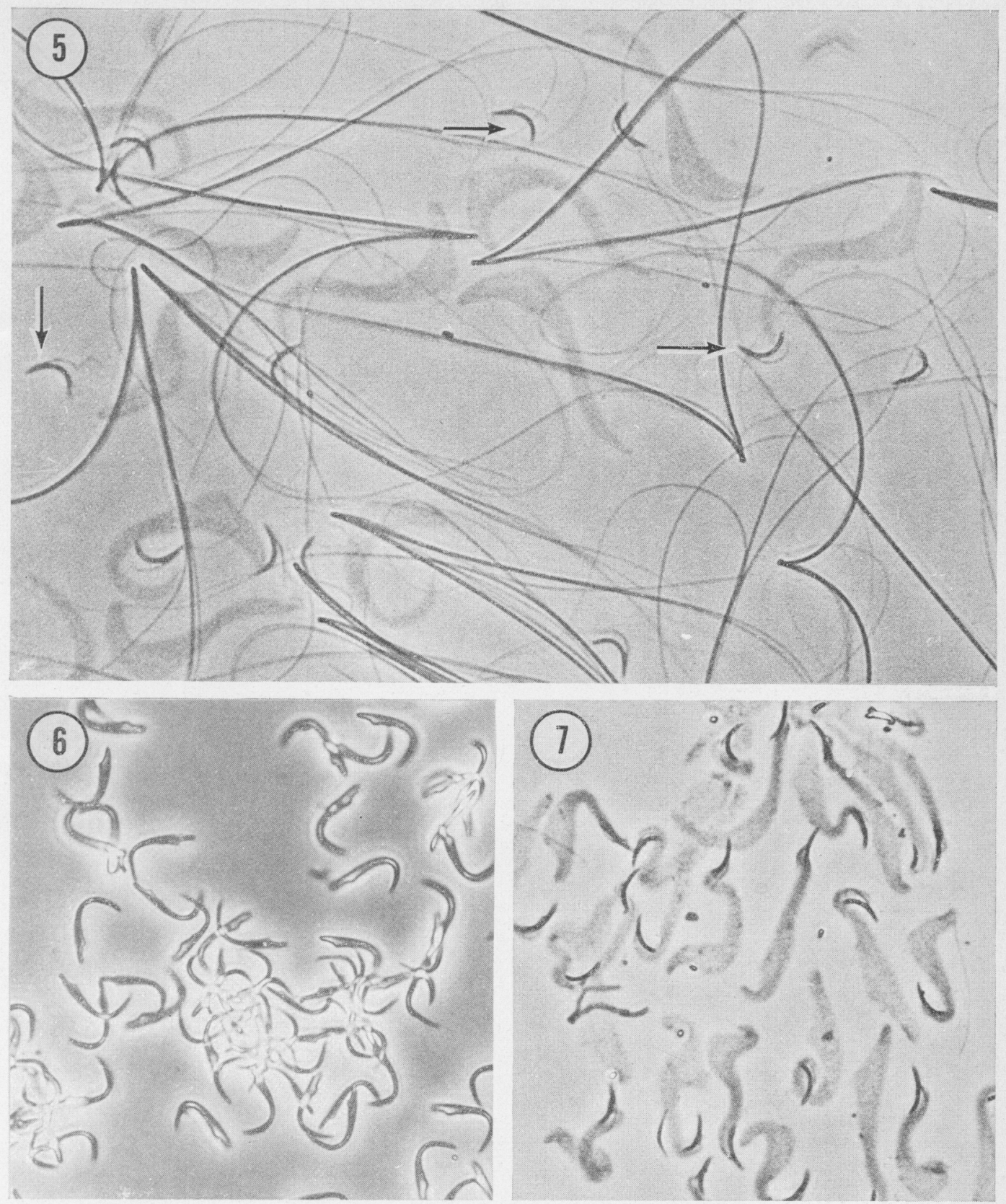

Fig. 5. Photomicrograph of rat spermatozoa treated for $15 \mathrm{~min}$ with a solution of $1 \%$ sarkosyl $+2 \mathrm{~mm}$ DTT. The heads and tails have detached. The tails are frayed apart and reveal the subfibres of the flagellum. Note how the head has swollen and the perforatorium (arrows) is detached from the nucleus.

Fig. 6. Photomicrograph of intact sperm heads.

Fig. 7. Photomicrograph of sperm heads after a 15-min extraction in sarkosyl-DTT. Figs 6 and 7 are at the same magnification and give an indication of the extent of the nuclear swelling induced by the sarkosyl extraction medium. 
PLATE 4

8

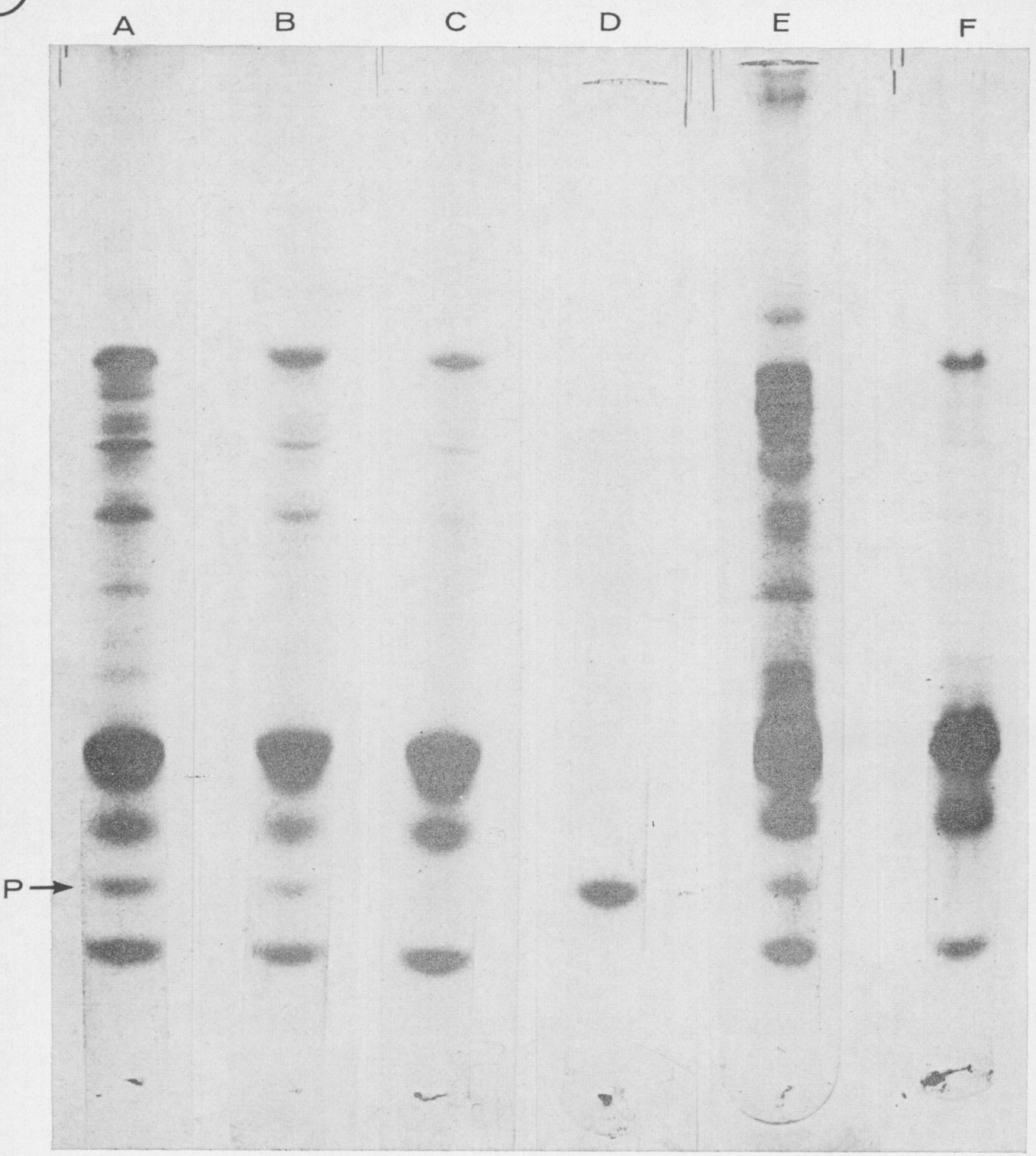

Fig. 8. SDS-polyacrylamide gel electrophoresis of polypeptides of rat spermatozoa. (A) After 15-min extraction in $1 \%$ sarkosyl, $2 \mathrm{~mm}$-DTT, $50 \mathrm{~mm}$-tris- $\mathrm{HCl}, \mathrm{pH} 9.0$. The bands range in molecular weights from 87,000 to 11,000 . Band $P$ (perforatorium) corresponds to a molecular weight of 13,000 . (B) The polypeptides resistant to sarkosyl extraction for $30 \mathrm{~min}$ are similar to those of $\mathrm{A}$ but some minor protein components are absent. (C) After extraction in sarkosyl-DTT for $1 \mathrm{hr}$ showing the absence of Band P. Morphological observation of the sperm fraction from which this gel was prepared showed that there were no intact perforatoria and only the outer dense fibres of the tails were present. (D) Sperm heads treated with sarkosyl-DTT for $30 \mathrm{~min}$. This sperm fraction contained only intact perforatoria and highly dispersed DNA from the sperm nuclei. Only one polypeptide, equivalent to Band P and with a mol. wt of 13,000, is present. (E) Proteins of spermatozoa from the cauda epididymidis resistant to solubilization by SDS in the absence of a disulphide bond-reducing agent. Note that the polypeptide band corresponding to the perforatorium (Band $\mathrm{P}$ ) is present in gel $\mathrm{E}$ but not in $\mathrm{F}$, indicating that during epididymal transit this polypeptide becomes more resistant to solubilization. (F) Proteins of spermatozoa from the caput epididymidis resistant to solubilization by SDS in the absence of a disulphide bond-reducing agent. 
This finding gives biochemical confirmation of the previous studies (Calvin \& Bedford, 1971; Bedford \& Calvin, 1974), which demonstrated that during epididymal transit several specific sperm structures accumulate disulphide bonds and become resistant to detergent solubilization.

Analysis of the amino acids of the perforatorium (Table 2) shows that the protein is characterized by $6.5 \%$ cysteine, and in contrast to the chromatin-associated proteins of mammalian spermatozoa (Coelingh et al., 1969, 1972; Kistler et al., 1973), it exhibits a relatively low arginine content.

The function of the perforatorium is as yet unclear, but its resistance to solubilization by SDS (Calvin \& Bedford, 1971) and by the various agents tested in the present study, and the fact that its appearance remains relatively unchanged during sperm penetration of the egg (Yanigamachi \& Noda, 1970) suggests a structural role.

This work was supported by USPHS grants HD-04290, HD-02344 and HD-08258 while G.E.O. was a Population Council Fellow and D.W.H. a USPHS Research Career Development Awardee.

\section{References}

Austin, C.R. \& Bishop, M.W.H. (1958) Some features of the acrosome and perforatorium in mammalian spermatozoa. Proc. R. Soc. B 149, 234-240.

Bedford, J.M. \& Calvin, H.I. (1974) The occurrence and possible functional significance of $-\mathrm{S}-\mathrm{S}$ - crosslinks in sperm heads, with particular reference to eutherian mammals. $J$. exp. Zool. 188, 137-155.

Calvin, H.I. \& Bedford, J.M. (1971) Formation of disulphide bonds in the nucleus and accessory structure of mammalian spermatozoa during maturation in the epididymis. J. Reprod. Fert., Suppl. 13, 65-75.

Clermont, Y., Einberg, E., Leblond, C.P. \& Wagner, S. (1955) The perforatorium-an extension of the nuclear membrane of the rat spermatozoon. Anat. Rec. 121, 1-12.

Coelingh, J.P., Rozin, T.H. \& Monfoort, C.H. (1969) lsolation and partial characterization of a basic protein from bovine sperm heads. Biochim. biophys. Acta 188, 353-356.

Coelingh, J.P., Monfoort, C.H., Roziln, T.H., Geversleuven, J.A., Schiphof, R., Steyn-Pawe,
E.P., Braunitzer, G., Schrank, B. \& Ruhfus, A. (1972) The complete amino acid sequence of the basic nuclear protein of bull spermatozoa. Biochim. biophys. Acta 285, 1-14.

Fairbanks, G., Steck, T.L. \& Wallach, D.F.H. (1971) Electrophoretic analysis of the major polypeptides of the human erythrocyte membrane. Biochemistry, N.Y. 10, 2606-2617.

FAwCETt, D.W. (1970) A comparative view of sperm ultrastructure. Biol. Reprod., Suppl. 2, 90-127.

GrEEN, W.W. (1940) The chemistry and cytology of the sperm membrane of sheep. Anat. Rec. 76, 455-473.

Kistler, W.S., Geroch, M.E. \& Williams-Ashman, H.G. (1973) Specific basic proteins from mammalian testes. Isolation and properties of small basic proteins from rat testes and epididymal spermatozoa. J. biol. Chem. 248, 4532-4543.

MANN, T. (1964) The Biochemistry of Semen and of the Male Reproductive Tract. Methuen, London.

YANAGIMACHI, R. \& NoDA, Y.D. (1970) Ultrastructural changes in the hamster sperm head during fertilization. J. Ultrastruct. Res. 31, 465-485.

Received 23 December 1975 